\title{
Should we Leave Nature Unattended or Assist through Enrichment to Foster Climate Change Mitigation? Exclosure Management in the Highlands of Ethiopia
}

\author{
Hadgu Hishe ${ }^{1,2} \cdot$ Kidane Giday $^{1} \cdot$ Teshome Soromessa $^{3} \cdot$ Jose van Orshoven $^{2} \cdot$ Bart Muys $^{2} \cdot$ Ali Akbar Barati $^{4}$. \\ Saghi Movahhed Moghaddam ${ }^{5}$ Pinar Gökcin Ozuyar ${ }^{6} \cdot$ Hossein Azadi $^{7,8,9}$
}

Received: 7 December 2017 / Accepted: 26 January 2020

(c) Springer Science+Business Media, LLC, part of Springer Nature 2020

\begin{abstract}
In order to foster the potential of exclosures to sequester carbon, it is understood that they are increasingly assisted through enrichment planting. To study the impact of the enrichment planting on carbon sequestration process, five exclosures with enrichment planting and five pure naturally regenerated exclosures were selected. Along parallel transects, $20 \times 20 \mathrm{~m}$ plots were laid at $100 \mathrm{~m}$ intervals where all woody vegetations were counted and measured for their diameter and total height. For soil sampling, five subplots at the center and four at each corner of the plots were established. The samples were collected at a depth of $0-0.2 \mathrm{~m}$, and this procedure was repeated for each plot. In this case, when good management practices were implemented (such as Wukro exclosures), significant differences in organic soil carbon above the ground and the total carbon between naturally regenerated and enriched exclosures $(P<0.05)$ were found. The mean estimates of the above ground carbon, soil carbon, and total carbon were respectively 8.08, 31.04, and 39.12 ton/ha for natural regeneration vs. 7.94, 31.00, and 38.93 ton/ha for enriched regeneration. Lower altitudes had significantly higher soil organic carbon $(P<0.05)$ than the higher altitudes. However, the slope had an insignificant effect on carbon distribution. Enriched exclosures performed more poorly in carbon sequestration. This was possibly due to the disturbances caused by mass plantation and poor post plantation follow up, since improved performance $(P<0.05)$ was seen in one enriched exclosure with better management practices.
\end{abstract}

Keywords Exclosure $\cdot$ Enrichment $\cdot$ Natural Regeneration $\cdot$ Environmental Management $\cdot$ Carbon Sequestration $\cdot$ Slope

\section{Introduction}

Severe degradation of natural resources in Ethiopia (Tesfaye 2007) has occurred over the past millennia (Darbyshire et al. 2003). A number of alternative solutions have been proposed to address the problem of degradation of public property resources in Ethiopia. Exclosure has, for a long time, been among the top priorities of such interventions (Gebremedhin et al. 2002; Berhane and Meles 2014). Exclosures are areas that are intentionally protected from $\triangle$ Hossein Azadi

hossein.azadi@ugent.be

1 Department of Land Resource Management and Environmental Protection, College of Dryland Agriculture and Natural Resources, Mekelle University, Mekelle, Ethiopia

2 Department of Earth and Environmental Sciences, University of Leuven, Leuven, Belgium

3 Center for Environmental Science, College of Natural Scienec, Addis Ababa University, Addis Ababa, Ethiopia

4 Department of Agricultural Management and Development, University of Tehran, Tehran, Iran
5 Department of Agroecology, Environmental Sciences Research Institute, Shahid Beheshti University, Tehran, Iran

6 Faculty of Economics, Administrative and Social Sciences, Istinye University, Istanbul, Turkey

7 Department of Geography, Ghent University, Ghent, Belgium

8 Research Group Climate Change and Security, Institute of Geography, University of Hamburg, Hamburg, Germany

9 Faculty of Environmental Sciences, Czech University of Life Sciences Prague, Prague, Czech Republic 
human and livestock interference to allow rehabilitation of degraded areas through natural regeneration (McIntosh et al. 1997). Exclosures especially have become huge resources in the north of Ethiopia (Berhane and Meles 2014) because of their role in reversing land degradation, and as carbon sinks, they are potential contributors to the mitigation of climate change through actions.

However, the experience with exclosures and community woodlots in Ethiopia before 1991 was disappointing. The factors liable for explaining the poor performance of the environmental reclamation program were inadequate scientific and technical knowledge, lack of a standardized approach aligned on the local agroecological conditions, and failure to integrate the views and interests of the rural population whom the program was intended to serve (Gebremedhin et al. 2002).

Though the performance of exclosures was poor in the beginning in Ethiopia (Gebremedhin et al. 2002), they have continued to be promoted as a means of rehabilitation of degraded lands by national and regional authorities and have been steadily increasing since 1991. Since then, tangible improvements have been recorded in restoring degraded areas and overall greenness of the region (Berhane and Meles 2014; Mengistu et al. 2005). Reports by Mengistu et al. (2005), Mekuria et al. (2007) demonstrated that establishment of exclosures on communal grazing lands and waste lands resulted in improved regeneration of indigenous species, biodiversity, and both below and above ground carbon (AGC) stock, which makes exclosures one of the best choices for land management options in the face of current climate change realities in Ethiopia.

Currently, frequent attempts are made to enhance natural regeneration by enrichment plantation, i.e., supplementing natural processes by active planting of more specimens of local species (Aerts et al. 2006). The main goals of such enhancement are to increase ground cover and reduce the impact of land degradation (especially in places where the focus is on soil and water erosion) (Berhane and Meles 2014). Over time, by increasing the existing stock of similar plants, the total biomass/carbon can be accelerated.

Since the soils in Tigray are rich in seeds (seedbank) (Reubens et al. 2007), and the success of the enrichment is rarely assessed, people are making the argument that just leaving things in the hands of Mother Nature is enough and is sometimes better than assisted regeneration (Letcher and Chazdon 2009). It also avoids disturbances and minimizes the cost of establishment.

The enrichment plantation program in Tigray is a good intention. However, the potential of enrichment plantation and its success as a means to enhance the rate of aerial vegetation coverage and amount of carbon fixation, in comparison with exclosures originated from natural regeneration, have (in reference to their success) never been studied in the region. Therefore, the success of the enrichment plantings was assessed in terms of productivity, specifically for their potential to sequester carbon in their vegetation and soil under the exclosures by comparing with the control site (exclosure without enrichment) per hectare basis. This study strives to answer two main questions: (1) Should we exclose and let nature do the rest or assist nature to facilitate carbon storage underground (soil) and above ground (vegetation), and contribute to mitigate the effect of climate change? (2) Do AGC, soil organic carbon, and total organic carbon vary with altitude and slope?

\section{Methodology}

\section{Description of the Study Area}

The research study is carried out in the mid and highlands (>1500 m) of Tigray (Fig. 1), to the northernmost point of Ethiopia following Mekuria and Aynekulu (2011) who have conducted similar studies by comparing open land, grazing land, and exclosures. These are Atsbi Womberta, Wukro, Hawzien, Samire, and Alamata. These districts were selected mainly because of their particular exclosure types that the study requires. Because most exclosures in Tigray are under enrichment plantation, exclosures with passive regenerations are rarely found concentrated in a district to the level of replication that this research demands.

In all exclosures, dominant species are acacia species and Dodonea angustifolia except in Atsbi where both Olea europaea subsp. cupsidata (olive) and Juniperus procera (juniper) are dominant, supplemented by Acacia species and Dodonea. Here it is good to mention that there are olive and juniper in Astibi as part of the enrichment planting and natural regeneration in addition to the acacia and dodonea. However, in other exclosures, acacia and dodonea dominate the natural regeneration and planted species. In the replicates of each district, maximum effort is made to keep species composition, soil, altitude, and slope factors similar. In all districts, planted species are similar to those existing in the exclosures. With regard to temperature and rainfall, we wanted to indicate the mean annual temperature and rainfall for each district. When we say 350-750 for example, there are replicates that receive 350 and others that receive 750 . However, the replicates within a district get similar rainfall and temperature. This helps us to make a better conclusion on the status of enrichment plantation in the wide range of the mid and high lands of the region which have different environmental conditions. We wanted to see if the results hold true across these districts (Ethiopian Meteorological Service Agency 2007). 


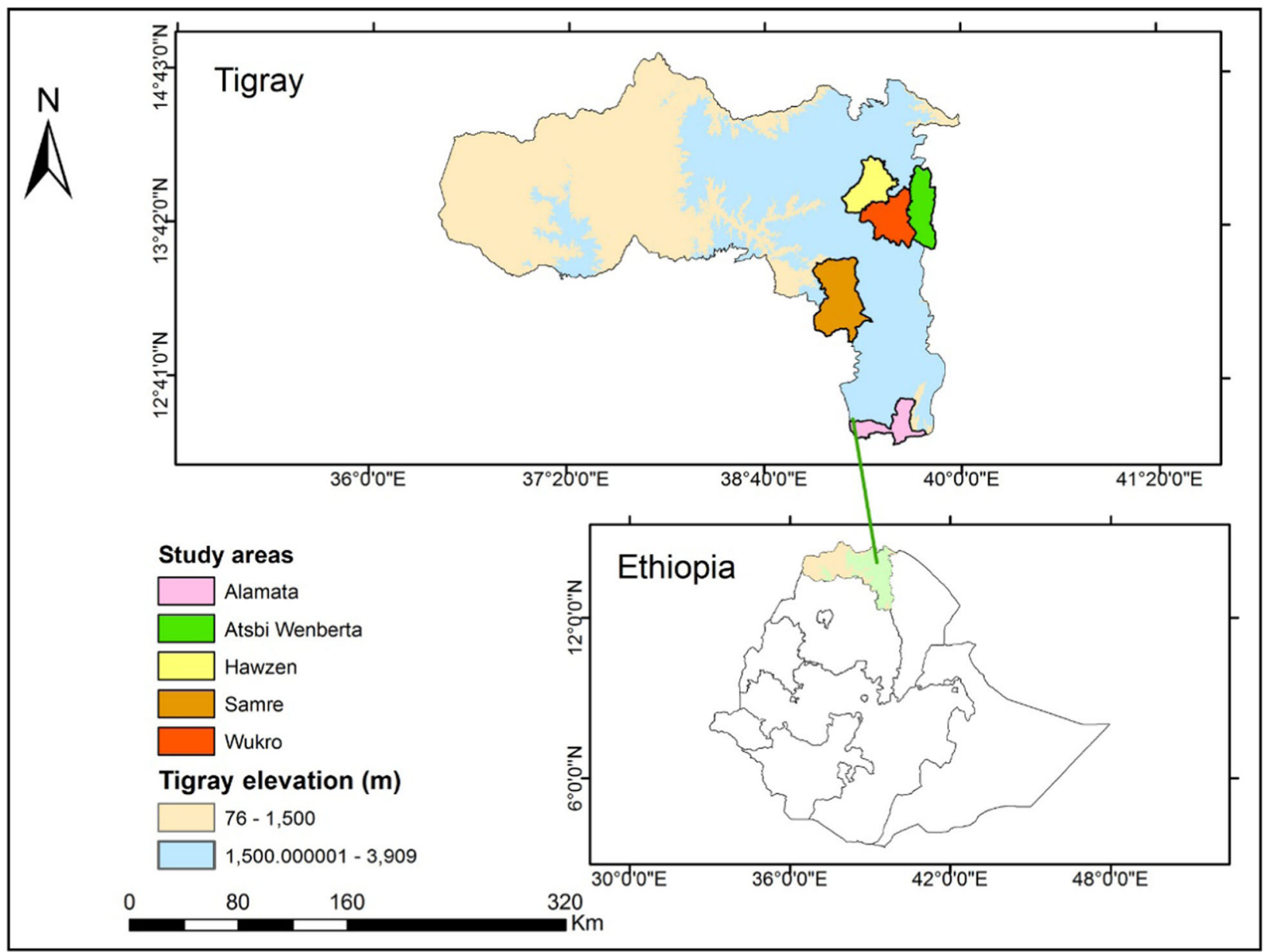

Fig. 1 Study areas

\section{Experimental Design and Data Collection}

To compare and evaluate the amount of carbon stored (below and above ground), two exclosures with different management interventions were selected purposely so as to keep other factors such as climate, topography, vegetation composition, and soil type uniform ( $\mathrm{Li}$ et al. 2017). Ten exclosures in five districts having one exclosure with enrichment plantation and one without enrichment plantation in each district were selected. In each district, the exclosure was selected purposively to have similar topography, soil, and climate conditions. Transect lines oriented from higher to gentle slopes (Fig. 1) were established systematically to include all variations within each site. Transect lines were laid at a distance of 200-500 $\mathrm{m}$ from each other depending on the size and homogeneity of the exclosures. The number of transects varied from five to six depending on the geometry of the sites. In order to avoid the edge effect, the transect lines had to start at $50 \mathrm{~m}$ from either of the edges. Within each transect line, plots of $20 \times 20 \mathrm{~m}$ (Fig. 2) were laid, placed $50-100 \mathrm{~m}$ apart at a horizontal distance depending on the topography of the sites. In total, 316 plots,
158 plots per exclosure management practice were recorded with 31-33 plots per each exclosure site. In each plot, and for each tree and shrub occurrence, we measured the diameter at breast height or stump height, respectively, using a caliper and the total height using clinometers and meter tape. The number of tree occurrences of species was recorded. The slope of each plot was measured using a clinometer.

For soil sampling, five $1 \times 1 \mathrm{~m}$ subplots (Fig. 2) were established at the center of every plot and four at each corner of the plots. Soil samples were collected at a depth of $0-0.2 \mathrm{~m}$ as the organic carbon is mostly concentrated at the surface profile depth. Composite soil samples were prepared by mixing the samples thoroughly, labeled in the field and taken to a laboratory for analysis. For bulk density, soil samples were extracted using a core sampler. All exclosures were within the age range of 13-15 years. Attentive care was taken to make replicate samples around the same age.

\section{Key Informant Interview}

To collect general information on planting conditions and postplanting management aspects of the districts, interviews 


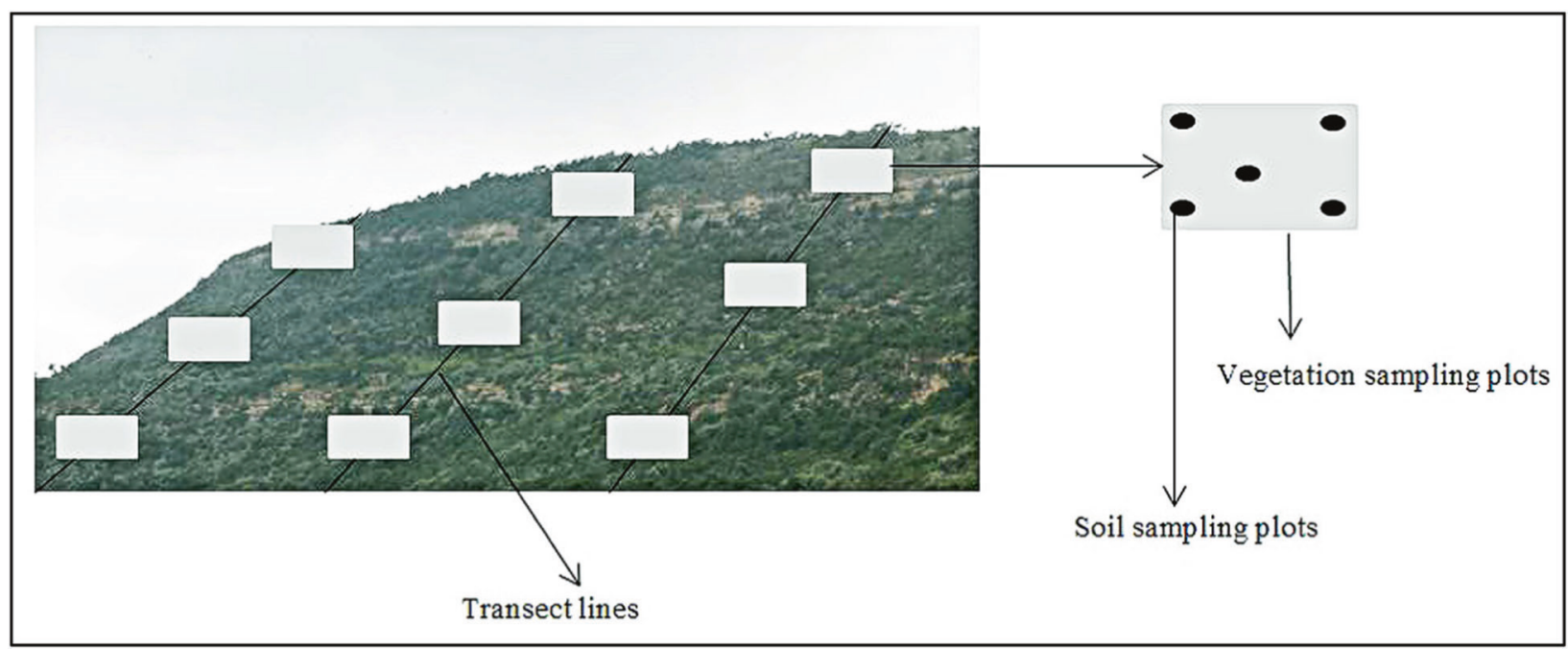

Fig. 2 Experimental design for vegetation and soil sampling

were held with key informants of each district along with natural resources experts and heads of their field who are directly involved in the plantation process and guards of each exclosure, to further strengthen and cross-check the views of the experts. During the key informant interviews, the following issues have been administered: questions on the establishment process and planting and postplanting management of the exclosures. The interviews attempt to raise questions that can increase the validity of the participants' answers. In each pair of exclosures, the following key informants were interviewed: (a) three experts from the district, (b) three development officers from the village (where the exclosures were found), (c) four guards from the exclosures, and (d) one head of the district's natural resource management. The main objective of the interview was to cross-check the information obtained from the district on the overall conditions of the exclosures.

\section{Data Analysis}

The amount of carbon stored in each species within the plots was estimated using the allometric equation following Kuyah et al. (2014) and WBISPP Woody Biomass Inventory and Strategic Planning Project (2000) for trees and shrubs, respectively. These models were chosen based on the fact that they were developed for similar vegetation in a similar ecosystem and have high coefficients of determination $\left(R^{2}=0.96\right.$ and 0.93 , respectively). This is given by the following formula:

$$
\begin{gathered}
Y=0.1428 \times \mathrm{DBH}^{2.2471}, \\
Y=(0.3197 \times \mathrm{DSH})+\left(0.0383 \times \mathrm{DSH}^{2.6}\right) \\
\left(R^{2}=0.93\right),
\end{gathered}
$$

where $\mathrm{Y}$ is the above ground biomass $(\mathrm{kg}), \mathrm{DBH}$ is the diameter at breast height (trees) in $\mathrm{cm}$, and DSH is the diameter at stump height (shrubs) in $\mathrm{cm}$ (WBISPP 2000). The total biomass of the exclosures was estimated by adding all the above ground biomass of trees and shrubs within all plots. To convert the biomass into carbon, we used the standard conversion factor of 0.5 as recommended by IPCC (2006).

$$
\text { Carbon stock }=\text { Biomass } \times 0.5 \text {. }
$$

To determine soil organic carbon stock, soil samples were analyzed. For this analysis, the composite soil samples were air dried, grounded, and passed through $2 \mathrm{~mm}$ sieve in preparation for laboratory analysis. Soil organic matter was determined following the procedures outlined by Walkley and Black (1934), and soil bulk density was determined using the core method (Mekuria et al. 2007). According to the average bulk density of an exclosure was used to calculate the soil carbon per plot to avoid the overestimation of soil carbon due to changes in bulk density.

Then, soil organic carbon in the $0-0.2 \mathrm{~m}$ layer was calculated using the following formula:

$$
\operatorname{SOC}\left(\mathrm{MgCha}^{-1}\right)=\operatorname{WBC}(\%) \times 10 \times \mathrm{Bd}\left(\mathrm{g}^{\mathrm{cm}-3}\right) \times 2,
$$

where WBC is the Walkley-Black carbon (Walkley and Black 1934), and Bd is the bulk density.

\section{Statistical Analysis}

One-way ANOVA was used to see if there is a difference in the amount of above ground, below ground, and total carbon in each of the two management regimes. To compare the 
effect of topographic positions (mainly elevation and slope) and enrichment planting on the carbon distribution along the landscape, general linear models, a multivariate analysis with the AGC soil organic carbon, and total organic carbon were the dependents, and treatment, enrichment condition, slope, and altitudes were the covariates which were used and run in SPSS software. Descriptive statistics were also used.

\section{Results}

\section{Planting and Post Management}

In all the districts, site preparation and planting seasons are similar. They become completed in May and June. The planting time varies with the amount of rain that the sites receive. Therefore, depending on the amount of rain, the sites' planting days may vary from mid July to mid August.

In all districts, the site preparation and mass planting are always completed by motivating the local community. However, the postplanting management (such as weeding and creating space for the new seedlings, opening canopy, and watering in the dry seasons) is almost neglected in all districts, though better practices are shown in the Wukro and Atsbi sites. Although such practices are not consistent enough, the dead seedlings are replaced during the first inventory check and while watering in Wukro.

\section{Above Ground and Soil Carbon under Different Exclosures}

The AGC varies among sites ranging from 5.78 to 11.4 ton/ ha in natural regeneration and from 5.61 to 10.72 ton/ha in assisted regeneration exclosures (Table 1). The average AGC in natural regeneration exclosures was slightly higher than those enriched exclosures (Table 1). However, the difference was not significant $(P>0.05)$.

Within the replicates, two contradictory results were found. In Alamata Acacia woodlands, the natural regeneration exclosures had significantly $(P<0.05)$ higher AGC, soil organic carbon, and total organic carbon than the enriched exclosures (Table 1). However, in the exclosures of Wukro site, the enrichment plantation contributed significantly $(P<0.05)$ to the AGC, soil organic carbon, and total organic carbon stored in the exclosures (Table 1) compared with the left alone exclosures.

The soil organic carbon within the naturally regenerated exclosures oscillated between 26.73 and 35 ton/ha; it was between 26.21 and 38.07 ton/ha for the enriched exclosures (Table 2). However, the average soil organic carbon for both exclosure types was similar with no significant difference $(P>0.05)$.
Table 1 Average above ground, soil organic, and total organic carbon by sites and treatments (ton/ha)

\begin{tabular}{|c|c|c|c|c|c|c|}
\hline \multirow{3}{*}{ Replications } & \multicolumn{6}{|c|}{ Treatment } \\
\hline & \multicolumn{3}{|l|}{ NR } & \multicolumn{3}{|l|}{$\mathrm{AR}$} \\
\hline & AGB & SOC & TOC & AGB & SOC & TOC \\
\hline Alamata & 11.4 & 35.16 & 46.56 & 9.82 & 30.46 & 40.28 \\
\hline Hawzien & 6.29 & 27.72 & 34.01 & 6.58 & 27.56 & 34.14 \\
\hline Wukro & 8.72 & 33.43 & 42.15 & 10.72 & 38.07 & 48.77 \\
\hline Atsbi & 8.23 & 32.14 & 40.37 & 6.98 & 32.69 & 39.67 \\
\hline Samire & 5.78 & 26.73 & 32.51 & 5.61 & 26.21 & 31.82 \\
\hline Sum & 40.42 & 155.18 & 195.6 & 39.72 & 154.99 & 194.68 \\
\hline Average & 8.08 & 31.04 & 39.12 & 7.94 & 31.00 & 38.93 \\
\hline
\end{tabular}

Table 2 The effect of treatment, altitude, and slope on different versions of carbon on exclosures

\begin{tabular}{llrlrll}
\hline Source & \multicolumn{7}{l}{ Tests of Between-Subjects Effects } \\
\cline { 2 - 7 } & $\begin{array}{l}\text { Dependent } \\
\text { Variable }\end{array}$ & $\begin{array}{l}\text { Sum of } \\
\text { Squares }\end{array}$ & df & Mean Square & F & Sig. \\
\hline Altitude & AGC & 157.291 & 1 & 157.291 & 9.957 & 0.002 \\
& SOC & 424.039 & 1 & 424.039 & 1.872 & 0.006 \\
& TOC & 1097.926 & 1 & 1097.926 & 3.434 & 0.035 \\
Slope & AGC & 0.115 & 1 & 0.115 & 0.007 & 0.932 \\
& SOC & 190.799 & 1 & 190.799 & 0.842 & 0.359 \\
\multirow{5}{*}{ Treatmenty } & TOC & 181.459 & 1 & 181.459 & 0.568 & 0.452 \\
& AGC & 1.688 & 1 & 1.688 & 0.107 & 0.744 \\
& SOC & 178.627 & 1 & 178.627 & 0.788 & 0.375 \\
& TOC & 215.202 & 1 & 215.202 & 0.673 & 0.413 \\
\hline
\end{tabular}

Following the AGC, similar results were also observed in the soil organic carbon within the replicates. In Alamata, the soil organic carbon under the natural regeneration exclosures was significantly higher $(P<0.05)$ than the soils under the enriched exclosures. In contrary to this, the soil organic carbon in enriched exclosures of Wukro was significantly higher $(P<0.05)$ compared with those under the naturally regenerated exclosure. In the rest of the other replicates, the soil organic carbon under both exclosures remained quite similar $(P>0.05)$.

The average total organic carbon (the sum of the average AGC and average soil organic carbon) in naturally regenerated and enriched exclosures were 39.12 and 38.93 ton/ha, which is slightly higher in the naturally regenerated exclosures (Table 1). The difference, however, is not statistically significant $(P>0.05)$.

\section{Above Ground and Soil Organic Carbon and Landscape Position}

Among the samples along the landscape in both treatments, significant difference $(P<0.05)$ was found in AGC distribution along altitudinal gradient. However, slope introduced insignificant $(P>0.05)$ differences in the carbon 
distribution in all investigated sites (both treated and untreated exclosures).

Similar to our results of the AGC accumulation along the landscape, soil carbon was affected significantly by altitude $(P<0.05)$ but not by slopes $(P>0.05)$ in both exclosure types. While soil organic carbon was higher in the lower altitudes than the higher altitudes, it was similar along the slope gradient. Although the altitude $(P<0.05)$ was significantly affected AGC, the total organic carbon difference along landscape positions remained nonsignificant $(P>$ 0.05 ) in both altitude and slope.

\section{Discussion}

This paper addressed the effect of enrichment plantation on the naturally regenerated exclosure and the potential of carbon sequestration, i.e., both above ground and soil organic carbon. The effect of topographical variables, mainly altitude and slope, on the distribution of both above ground, soil, and total carbon levels of exclosures was investigated. Topographic effects were considered mainly to see whether enrichment plantations at different positions have different contributions to the above, soil, and total organic carbon of the exclosures.

\section{Above Ground and Soil Carbon under Different Exclosures}

The enrichment planting on the naturally regenerated exclosures did not offer additional AGC and any additional returns to the soil carbon stock. Another indicator for the inefficiency of the enrichment plantations is the fact that "the average AGC in enriched exclosures is expected to be higher than the exclosures without enrichment" (Giday et al. 2013). For example, according to Mekuria et al. (2017), the range of the exclosures of the AGC in this region is between 4 and 14 ton/ha. However, our results showed that the average AGC of the enriched exclosures was not better than the regional average.

The reasons for the poor performance of enrichment on exclosures are multifaceted. In Tigray, after seedlings are planted, they are deprived of any postplanting care and eventually die out, and disturbances within the soil and soil seed banks and damages on standing trees due to mass planting are causing serious problems. Mass planting is done during the enrichment and hillside rehabilitation in Ethiopia and particularly in Tigray, which introduces disturbances such as uncovering the seeds and exposing them to desiccation, removing germinated seeds and established seedlings during site preparation such as pit digging (Wassie et al. 2009), and damaging well established plants. Soil compaction during mass plantation decreases the viability of seeds already in the soil and the vigor of saplings (Vieira and Scariot 2006; Sansevero et al. 2011), which is also another seriously damaging ecological factor in these exclosures.

Added carbon on vegetation is a direct result of added growth through photosynthesis (Giday et al. 2013). Beyond planting, especially in the dry areas where water is a limiting factor, seedlings need a continuous supply of water, reducing competition from nearby well established plants (Mekuria and Ayenekulu 2011; Giday 2013). Under similar conditions, differences in above ground biomass can bring a difference in the soils organic carbon (Mekuria and Aynekulu 2011). The insignificant difference in soils organic carbon under the naturally regenerated and enriched exclosure of this study is explained by the nonsignificant difference in the AGC (Mekuria et al. 2014). In drylands like the study area, focusing only on planting and ignoring postplanting management is unlikely to influence the overall performance of the exclosures positively (Mekuria and Aynekulu 2011). The findings of the present study are consistent with the findings of Bikila et al. (2016) and Mekuria (2013) in which soil organic carbons for exclosures were found to be higher than open grazing areas. Similarly, Li et al. (2012) reported grazing exclusion as a positive way to restore deserted ecosystems which has a high potential for sequestering soil carbon in the semi-arid Horqin Sandy Land.

Therefore, in Tigray where success is recorded in most exclosed degraded areas (Berhane and Meles 2014; Mengistu et al. 2005) through natural regeneration, enrichment plantings are done at the cost of these all losses plus the multiple resources invested each year for nursery raisings, transportation, and plantings. The outcomes, however, do not explain the efforts and investments incurred on the exclosures in the process of enrichment planting.

Even in the dry lands, however, enriching remnant forests and exclosures is a promising strategy to foster biomass/carbon accumulation if proper management is assumed (Giday et al. 2013). A meta-analysis by Dlamini et al. (2016) reported that natural forest lands degradation significantly reduced soil organic stocks by $16 \%$ in dry climates $(<600 \mathrm{~mm})$ compared with $8 \%$ in wet climates $(>1000 \mathrm{~mm})$. Improved grazing, fertilization, sowing of legumes and improved grass species, irrigation, and cultivation conversion all contributed to the improvement of forests. Conant et al.'s synthesis (2017) also suggested that improved biomass/carbon accumulation, in combination with other factors, tends to lead to an increase in soil carbon at rates ranging from 0.105 to $>1 \mathrm{MgC} \mathrm{ha}^{-1}$ year $^{-1}$.

The results of Wukro's exclosure, where better postplanting operations are carried out, show that enrichment plantations have significantly increased the amount of organic carbon, i.e., both above ground and soil carbon. In 
Table 3 The topographic features of different districts

\begin{tabular}{|c|c|c|c|c|c|c|c|}
\hline \multirow[t]{2}{*}{ Sites } & \multirow[t]{2}{*}{ Treatment $^{\mathrm{a}}$} & \multicolumn{2}{|c|}{ Altitude (M) } & \multicolumn{2}{|c|}{ Slope(Deg) } & \multirow[t]{2}{*}{ Average daily temperature } & \multirow[t]{2}{*}{ Rainfall annual } \\
\hline & & Min & Max & Min & Max & & \\
\hline \multirow[t]{2}{*}{ Alamata } & 1 & 1646 & 2151 & 4.04 & 24.25 & \multirow[t]{2}{*}{$23^{\circ} \mathrm{C}$} & \multirow[t]{2}{*}{$831 \mathrm{~mm}$} \\
\hline & 2 & 1638 & 2126 & 5.06 & 21.31 & & \\
\hline \multirow[t]{2}{*}{ Hawzien } & 1 & 1738 & 2073 & 13.25 & 25.6 & \multirow[t]{2}{*}{$20^{\circ} \mathrm{C}$} & \multirow[t]{2}{*}{$662 \mathrm{~mm}$} \\
\hline & 2 & 1757 & 2047 & 14.65 & 22.72 & & \\
\hline \multirow[t]{2}{*}{ Wukro } & 1 & 1772 & 2264 & 2.59 & 21.04 & \multirow[t]{2}{*}{$19.2^{\circ} \mathrm{C}$} & \multirow[t]{2}{*}{$610 \mathrm{~mm}$} \\
\hline & 2 & 1763 & 2209 & 2.43 & 24.11 & & \\
\hline \multirow[t]{2}{*}{ Atsbi } & 1 & 2226 & 2765 & 2.35 & 25.83 & \multirow[t]{2}{*}{$18^{\circ} \mathrm{C}$} & \multirow[t]{2}{*}{$668 \mathrm{~mm}$} \\
\hline & 2 & 2217 & 2741 & 2.22 & 24.71 & & \\
\hline \multirow[t]{2}{*}{ Samire } & 1 & 1730 & 2332 & 1.91 & 19.33 & \multirow[t]{2}{*}{$20^{\circ} \mathrm{C}$} & \multirow[t]{2}{*}{$600 \mathrm{~mm}$} \\
\hline & 2 & 1757 & 2373 & 1.90 & 19.76 & & \\
\hline
\end{tabular}

${ }^{\mathrm{a}}$ Treatment, $1=$ Control, $2=$ enriched contrast with liability to poor management and disturbances during enrichment planting on existing plant stock, enrichment planting has negatively affected the above ground and soil organic carbon, as in the case of Alamata. This is because the exclosures are disturbed from the site preparations to the planting, and the planted seedlings do not survive, and this causes a double failure. The success so far documented in Tigray's exclosures is recorded only because of the exclusion of disturbances from both animals and humans. The results of studies by Mengistu et al. (2005) and Berhane and Meles (2014) are in line with the current study results that enrichment planting and human interference, and no additions have been made to the carbon accumulation of the exclosures.

Enrichment plantations need attentive follow-ups until the seedlings are able to stand alone as they have replaced the potential emergent seedling from soil banks (Marod et al. 2004). Otherwise, planting alone, mainly in water deficient areas, reduces the survival rates, loss of soil seed banks, and emergent seedlings (Wassie et al. 2009), which could have a positive contribution to carbon sequestration, both on the above ground soil and in the potential for the exclosures. The results of permanent plot experiments of Desa'a forest (Giday et al. 2013) are good evidence for the effectiveness of the enrichment plantation in enhancing the competency of exclosures to sequester increased carbon dioxide if efficient monitoring and postplanting tending operations are implemented. Sheltering seedlings, pruning above canopy, and thinning around the planted seedlings have significantly contributed to the growth of seedlings in both diameter and height (Giday et al. 2013), and this has a direct influence on the carbon accumulation of the seedlings (Mekuria and Ayenekulu 2011; Giday et al. 2013) within the same region consisting of a similar environmental setup. This is also similar to the study reported by Getnet (2015) for Yeka Forest (144.75 ton $\mathrm{ha}^{-1}$ ). As a result, trees with higher overground and lower ground biomass contribute more to soil carbon sequestration than shrubs or herbs. The accumulation of soil organic carbon also depends on the amount of litter (Lemma et al. 2007) and root activity, such as rhizodeposition and decomposition. In addition, Dawit et al. (2002) found that land use and land cover change could have an impact on the amount and composition of soil organic matter through their influence on decomposition and humidification processes. Proper forest management could increase the carbon density of the overground vegetation and increase the carbon storage potential in the soil.

However, because of the absence of these pre and postplanting follow-ups, enrichment plantings have failed to survive and contribute to the overall carbon stock in the exclosures of the study areas.

\section{Above Ground and Soil Organic Carbon and Landscape Position}

The topographic features of different districts were different, though it was similar for the sites within each district (Table 3).

While nonsignificant differences in AGC were recorded amongst the samples along the landscape due to slope differences, altitude has introduced significant differences in the carbon stored in the vegetation in both treatments. This is probably due to the difference in growing conditions like soil depth, fertility, and exposure to different environmental conditions such as wind and frost as altitude increases (Yusran 2010).

Similar to our results of AGC accumulation along the landscape, soil carbon shows a significant difference with higher soil organic carbon in the lower altitudes than the higher altitudes. This might be attributed to soil organic carbon downward movement due to soil erosion agents. Soil erosion increases as the slope and altitude increase, thereby, redistributing the soil organic carbon to the lower 
altitude and gentle slopes (Gregorich et al. 1998). Leaching may also have a significant contribution (Yusran 2010). Similar results were reported where increased slopes were coupled with higher altitudes, and this has a significant effect on the overall properties of the soils such as texture, depth, nutrient (Yusran 2010), and similarly, the soils organic carbon (Alcántara et al. 2014).

A significant difference in total organic carbon was obtained due to landscape positions, both altitude and slope. This is contrary to the studies of Mekuria and Ayenekulu (2011) where soil nutrients were not affected by the landscape positions within exclosures. The difference in the uniformity of growing conditions availability throughout the exclosure in the study area might explain the difference within the results. This difference can also be due to the physical soil and water conservations structure differences in the exclosures which reduces the effect of soil erosion (Kadlec et al. 2012).

Because of the significant differences in AGC and soil organic carbon altitudinal gradients, the total carbon was significantly affected by altitude. The higher altitude plots have retained lower total carbon than the lower altitude plots. Therefore, this can be explained by the possible movement of soil along the landscape, low favorable conditions for seed germination from the seed bank or lower availability of seed banks in the higher altitude for natural regeneration, and death or stunted growth of planted seedlings due to less soil fertility, soil depth, and extra transpiration as the exposure to wind increases, and the altitude increase is coupled with less attention than is required after plantation (Yusran 2010; Alcántara et al. 2014) due to different erosion agents (Kaldec et al. 2012).

\section{Conclusion}

In the northernmost point of Ethiopia, Tigray, the contribution of enrichment plantations increases the biomass and therefore, carbon stock in the exclosure is very low owing to low attention to the planted seedlings when it is summer and the rain has seared. The left alone untreated exclosures have promised to be better than the enriched exclosures under the current level of implementation processes and management. Considering all the physical efforts and financial expenditure required for enrichment plantation every year, it is better to exclose the degraded areas from any livestock and human interferences and let Mother Nature do the rest. However, indicators show that enrichment plantation on exclosures can be a big opportunity to maximize their potential to increase carbon levels both below and above ground if proper management procedures are followed. This can be confirmed from the results of Wukro site, specifically Abereha we Atsibeha, and the permanent plots of Desa'a, where better attention is observed all year round. Therefore, enrichment planting can play a crucial role in increasing the potential of exclosures to accumulate more carbon and therefore, play a significant part in mitigating the effects of climate change effectively compared with those that are left alone.

The distribution of AGC is uniform across the landscape showing uniform vegetation covering in the exclosures. However, soil organic carbon is significantly affected by both altitude and slope, showing management intervention is needed to be retained on site. Low performance of enrichment plantation in sequestering carbon dioxide is related to management constraints such as moisture deficit after the rain season has gone and nutrient competition with weeds begins, as well as the already established vegetation in the exclosures and excessive evapotranspiration.

Overall, without proper postplanting management, enrichment plantations on naturally regenerated exclosures in North Ethiopia will not increase the ground and soil organic carbon levels of accumulation under current management procedures.

Finally, since the above carbon and soil organic carbon may vary with another variable such as time, altitude, and slope, we suggest studying the importance of such variables in future studies.

\section{Recommendations}

To exploit the full potential of exclosures and put the huge resources spent every year in to effect, strategic modification in the overall process of plantation and enrichment has to be made. Such concerns are a result of periodic assessment of exclosure performances with regard to the intended goals, close follow-ups such as animal intrusions, moisture conservation, and careful attention during mass plantation to avoid deteriorating the emerging seedling from soil seedbanks and create awareness with regard to the process of natural regeneration which is required to minimize damages. Policy direction and strict follow up mechanisms are in demand to upgrade the role of exclosures to mitigate climate change and enhance green development in the region and country in general.

This study further recommends that increasing forest carbon stock can be achieved through sustainable forest management, including site preparation, species selection, and afforestation. Forest appears to offer a relatively lowcost approach to carbon sequestration and therefore, has a high potential to absorb carbon dioxide from the atmosphere, and the country could contribute to global climate change mitigation efforts. In this context, this study recommends planting new seedlings, promoting natural regeneration, and conserving degraded areas with local community participation, which should be pursued in order 
to maintain the existing carbon stock in the forest and increase its biomass in the future.

Future studies should emphasize the use of climate scenarios to simulate the nature and distribution of soil organic carbon, particularly below the subsoil, and assess various microbial activity proxies to study soil organic carbon dynamics with respect to land use change. Further studies should also focus on subsoil carbon dynamics across different agroecological zones, which are currently less reported in Ethiopia. Soil carbon modeling received very little attention in Ethiopia. Thus, we can increase our prediction of carbon dynamics by modeling changes in soil organic carbon across the soil profile. In addition to the establishment of long-term soil organic carbon, field studies currently lacking in Ethiopia, existing research efforts are focusing more on quality than on the quantity of soil organic carbon stored in different landscapes. Therefore, soil carbon modeling will provide a comprehensive understanding of soil organic dynamics in heterogeneous environments such as Ethiopia, stressing the need for further studies on the effect of management practices.

Acknowledgements This research is supported by funding from the Department for International Development (DfID) under the Climate Impact Research Capacity and Leadership Enhancement (CIRCLE) program.

\section{Compliance with Ethical Standards}

Conflict of Interest The authors declare that they have no conflict of interest.

Publisher's note Springer Nature remains neutral with regard to jurisdictional claims in published maps and institutional affiliations.

\section{References}

Aerts R, Overtveld KV, Mitiku H, Hermy M, Deckers J, Muys B (2006) Species composition and diversity of small Afromontane forest fragments in northern Ethiopia. Plant Ecol 187:127-142

Alcántara LP, García LB, Espejo GA (2014) Topography effect on soil organic carbon pool in Mediterranean natural areas (Southern Spain). Geophys Res Abstr 16:EGU2014-EGU15959

Berhane E, Meles K (2014) Community-managed exclosures in Tigray, Ethiopia, in Treesilience: An assessment of the resilience provided by trees in the drylands of Eastern Africa. ICRAF, Nayrobi, Kenya

Bikila NG, Tessema ZK, Abule EG (2016) Carbon sequestration potentials of semi-arid rangelands under traditional management practices in Borana, Southern Ethiopia. Agric Ecosyst Environ 223:108-114. https://doi.org/10.1016/j.agee.2016.02.028

Conant RT, Cerri CEP, Osborne BB, Paustian K (2017) Grassland management impacts on soil carbon stocks: a new synthesis. Ecol Appl 27(2):662-668

Darbyshire I, Lamb H, Umer M (2003) Forest clearance and regrowth in northern Ethiopia during the last 3000 years. Holocene $4: 537-546$
Dawit S et al. (2002) Soil organic matter dynamics in the subhumid agroecosystems of the Ethiopian highlands: evidence from natural 13C abundance and particle size fractionation. Soil Sci Soc Am J 66:969-978

Dlamini P, Chivenge P, Chaplot V (2016) Overgrazing decreases soil organic carbon stocks the most under dry climates and low soil pH: a meta-analysis shows. Agric Ecosyst Environ 221:258-269. https://doi.org/10.1016/j.agee.2016.01.026

Ethiopian Meteorological Service Agency (2007) Annual climate bulletin for the year 2007. Ministry of Water Resource, Addis Ababa, Ethiopia

Gebremedhin B, Pender J, Tesfay G (2002) Community natural resources management in the highlands of Ethiopia. Paper presented on International conference on policies for sustainable land management in the East African highlands. UNECA, Addis Ababa

Getnet A (2015) Forest carbon stock and variations along environmental gradients in Yeka forest and its implication for climate change mitigation a thesis submitted to center for environmental sciences. Ethiopia: Addis Ababa University

Giday K, Eshete G, Barklund P, Aertsen W, Muys B (2013) Wood biomass functions for Acacia abyssinica trees and shrubs and implications for provision of ecosystem services in a community managed exclosure in Tigray, Ethiopia. Journal of Arid Environments, 94, 80-86

Gregorich EG, Greer KJ, Anderson DW, Liang BC (1998) Carbon distribution and losses: erosion and deposition effects. Soil Tillage Res 47:291-302

HS Eggleston, L Buendia, K Miwa, T Ngara, K Tanabe (2006) IPCC guidelines for national greenhouse gas inventories. Forestry. The Institute for Global Environmental Strategies (IGES), Japan

Kadlec V, Holubík O, Procházková E, Urbanová J, Tippl M (2012) Soil organic carbon dynamics and its influence on the soil erodibility factor. Soil Water Resour 7(3):97-108

Kuyah S, Sileshi GW, Njoloma J, Mng'omba S, Neufeldt H (2014) Estimating aboveground tree biomass in three different miombo woodlands and associated land use systems in Malawi. Biomass Bioenergy 66:214-222

Lemma B et al. (2007) Factors controlling soil organic carbon sequestration under exotic tree plantations: a case study using the $\mathrm{CO}_{2}$ fix model in southwestern Ethiopia. For Ecol Manag 252 (1-3):124-131

Letcher SG, Chazdon RL (2009) Rapid recovery of biomass, species richness, and species composition in a forest chronosequence in Northeastern Costa Rica. Biotropica 41:608-617

Li S, Juhász-Horváthb L, Harrison PA, Pintér L, Rounsevell MDA (2017) Relating farmer's perceptions of climate change risk to adaptation behaviour in Hungary. J Environ Manag 185 (1):21-30

Li Y, Zhao X, Chen Y, Luo Y, Wang S (2012) Effects of grazing exclusion on carbon sequestration and the associated vegetation and soil characteristics at a semi-arid desertified sandy site in Inner Mongolia, northern China. Can J Soil Sci 92(6):807-819. https://doi.org/10.4141/cjss2012-030

Marod D, Kutintara U, Tanaka H, Nakashizuka T (2004) Effects of drought and fire on seedling survival and growth under contrasting light conditions in a seasonal tropical forest. J Veg Sci 15:691-700

McIntosh PD, Allen RB, Scott N (1997) Effects of exclosure and management on biomass and soil nutrient pools in seasonally dry high country, New Zealand. J Environ Manag 51 (2): $169-186$

Mekuria W, Aynekulu E (2011). Exclosure land management for restoration of the soils in degraded communal grazing lands in northern Ethiopia. Land Degradation and Development, 11p. (Online first). https://doi.org/10.1002/ldr.1146 
Mekuria W, Langan S, Noble A, Johnston R (2014) Soil Organic Carbon and Nutrient Contents are not influenced by Exclosures Established in Communal Grazing Land in Nile Basin, Northern Ethiopia. In: Proceedings of International Conference on Advances in Agricultural, Biological and Environmental Sciences, Dubai (UAE)

Mekuria W, Langan S, Noble A, Johnston R (2017) Soil restoration after seven years of exclosure management in northwestern Ethiopia. Land Degrad. Dev. 28(4):1287-1297

Mekuria W, Veldkamp E, Mitiku H, Nyssen J, Muys B, Gebrehiwot K (2007) Effectiveness of exclosures to restore degraded soils as a result of overgrazing in Tigray, Ethiopia. J Arid Environ 69:270-284

Mekuria W (2013) Conversion of communal grazing lands into exclosures restored soil properties in the semi-arid lowlands of Northern Ethiopia. Arid Land Res Manag 27(2):153-166. https:// doi.org/10.1080/15324982.2012.721858

Mengistu M, Teketay D, Håkan H, Yemshaw Y (2005) The role of enclosures in the recovery of woody vegetation in degraded dryland hillsides of central and northern Ethiopia. J Arid Environ 60:259-281

Reubens B, Heyn M, Genrehiwot K, Hermy M, Muys B (2007) Persistent soil seed banks for natural rehabilitation of dry tropical forests in northern Ethiopia. Tropicultura 25:4
Sansevero JBB, Prieto PV, de Moraes LFD, Rodrigues PJP (2011) Natural regeneration in plantations of native trees in lowland Brazilian Atlantic forest: community structure, diversity, and dispersal syndromes. Restor Ecol 19(3):379-389

Tesfaye A (2007) Plant diversity in Western Ethiopia: ecology, ethnobotany and conservation. Ph.D. thesis, Department of Biology, University of Oslo, Norway and Sweden

Vieira DL, Scariot A (2006) Principles of natural regeneration of tropical dry forests for restoration. Restor Ecol 14:11-20

Walkley A, Black IA (1934) An examination of the Degtjareff method for determining organic carbon in soils: effect of variations in digestion conditions and of inorganic soil constituents. Soil Sci 63:251-263

Wassie A, Sterck FJ, Teketay D, Bongers F (2009) Effects of livestock exclusion on tree regeneration in church forests of Ethiopia. For Ecol Manag 257:765-772

WBISPP (2000) Manual for woody biomass inventory. Woody biomass inventory and strategic planning project, Woody Biomass Inventory and Strategic Planning Project, Ministry of Agriculture, Addis Ababa, Ethiopia

Yusran FH (2010) Soil organic carbon losses: the balance between respiration and leaching, and phosphorus mobility in lateritic soils. J Tropic Soils 15(3):245-254 